\title{
Design and Simulation of Automatic Temperature Control and Alert System Based PIC16F887
}

\author{
Jabbar Shaati Jahlool \\ Computer Techniques Engineering Department, Dijlah University College, Baghdad, Iraq \\ e-mail: jabbar.shatti@duc.edu.iq
}

\begin{abstract}
In this research, the design and simulation of an automatic system for temperature control using embedded system in order to automatically control of multi appliances depend on the temperature value. The appliances will be controlled are ventilation, cooling, heating and alert. This is an order to avoid or reduce to human intervention and increase system reliability. An important feature of this automation process is to reduce or eliminate the possibility of relying on the human factor operator for industries, warehouses and laboratories, and to improve working and performance environments. The system in this paper used the microcontroller PIC16F887 as the central control unit, LM35 temperature sensor as a temperature source, $16 \times 2$ liquid crystal display (LCD) as indicator to display the different system working status an addition to some of drivers, relay and light emitting diodes (LED) as indicators to display the corresponding working appliance driver. The implementation and simulation of the system work has been achieved by using Proteus professional software $v 8.0$ and mikroc pro for pic v.6.6.1 software to write the equivalent program and generate. Hex file for system working.
\end{abstract}

Keywords: ATC, PIC16F887, LM35, PROTEUS, MIKROC

Copyright $\odot 2017$ APTIKOM - All rights reserved.

\section{Introduction}

Nowadays rely on automated systems became commonly used things in life and, of course, one of these systems has automatic temperature control. The use of automatic temperature control systems become now commonly used in a wide field like industrial plants, laboratories, medical and food stores, warehouses and other. Modern applications using temperature control systems based on microcontrollers (MCU) to control the ventilation, heat, cold and alarm devices for the one of above fields. The use of micro-controllers achieves great reliability as well as high efficiency [1]. Depending of using of MCU in embedded design has not only been increased but it achieved a revolutionary change. An important element for achieving competitiveness in manufacturers is to provide differentiation while maintaining or reducing cost and to expand their product functionality [2]. Save power and reduce the costs for optimization of smart home system this is study about internal temperature controlling system based on microcontroller [3]. Automatic smart kitchen system is used to discharge heat and smoke in the kitchen by using PWM (Pulse Width Modulation) waves generated by a PIC16F877A MCU based on temperature sensor to controlling the speed of kitchen air blower [4]. Using temperature control and peripheral interface controller (PIC) 16F876A but it focus on the use of external signal conditioning circuit for proper processing of the signal before it was given to $\mathrm{MCU}$, but this method increase the system hardware components then consequently lead to increase the cost and probability of fault by adding others hardware components, while the internal ADC (analogue to digital converter) circuit inside the MCUs take signal conditioning of all types of inputs analogue signals returned from different types of sensor in other consideration therefore this additional external circuit has not needed [5]. Temperature control in a ventilation system using PIC18F4620 was designed and developed by using heat resistor as the heating source to emits a heat quantity in the environment and direct current (DC) motor as the cooling source and then generate pulse width modulation (PWM) signal as a control speed dependent signal to control of the cooling depend on the heating difference [6]. An automatic control solution is suggested to control the fan speed by using the PIC 16F877A and LM35DZ temperature sensor the automatic design circuit control of fan speed depend on the change of temperature i.e. when the temperature is high, the fan operates at high speed and vice versa. This process occurs automatically [7]. Monitoring server room temperature has been implementation of a microcontroller based system by using 
kind of microcontroller (Atmel AVR ATmega8535 microcontroller and LM35 temperature sensor), other attached devices are used to display the room temperature as well as an alarm device is also used. The system is equipped with a GSM modem to send a text message when the room temperature rises to a certain extent to enter the danger zone to alert the room server supervisor for the purpose of controlling other electronic devices within the server room [8]. Designing and implementing a modern fan speed control system based on the changes that occur in the room temperature. This design is based on the use of PWM technology so that changing the duty cycle depends on the room temperature and as a result leads to the control of the fan speed movement automatically [9]. In this work, the designs of ATC system based a PIC microcontroller (PIC16F887) and temperature sensor (LM35) for automatically control of multi appliance depend on selected temperature values these will be lead to automatically change to appropriate appliance (ventilation, cooling, heating and alert). The proposed system implemented and simulated by using proteus professional software v 8.0 and mikroc PRO FOR PIC v.6.6.1. The object of this system to avoiding human intervention in such applications which then leads to eliminate or reduce dependency on humans workers for industries, warehouse, laboratories and as a result leads to improvement the working environments and performance.

\section{Description strategy of the proposed system}

The proposed design system are shown in the block diagram of Figure 1. The design using a MCU type PIC16F887 as a heart control unit of the system has built in analog to digital (ADC) convertor which receive the temperature from temperature sensor integrated circuit (IC) LM35, where it will control the three appliance and one alert device according to the environmental temperature changes which is calculated according to the setting values in the programming. The LM35 sensor connect to pin RA2 of PORTA of the (MCU) this pin must be setting as analogue input by TRISA and ANSEL register by the program setting. The LCD display connected as 4 bit mode, the 4 bit mode means connects data pins, D4 to D7 of LCD to MCU, in this design connect to PORTD of MCU. RC0 to RC2 from PORTC of MCU selected as a control pins connected to driver as a current source and then to relay in order to work the selected appliance required according to program statements. RC3 connect to alert driver to generate alert signal when the temperature degree exceed to 35 centigrade.

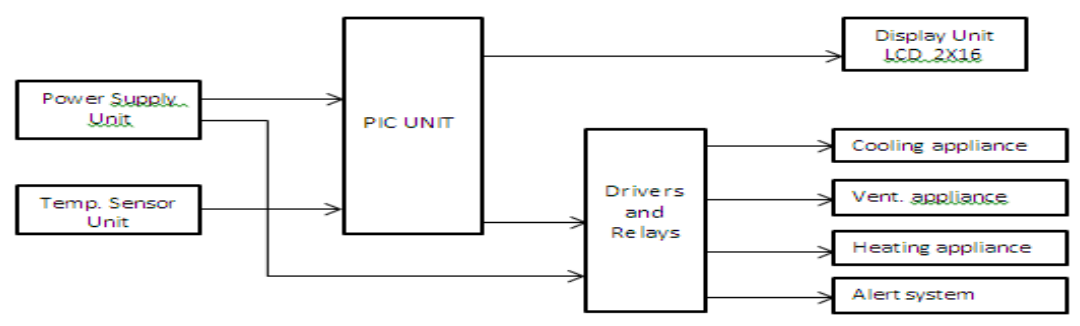

Figure 1. Block Diagram of the Proposed System

For purpose to supply electric power to operating the hardware electronics design circuit, five volts power supply is needed. Figure 2 schematic diagram showing the circuit that performs that purpose for the proposed system.

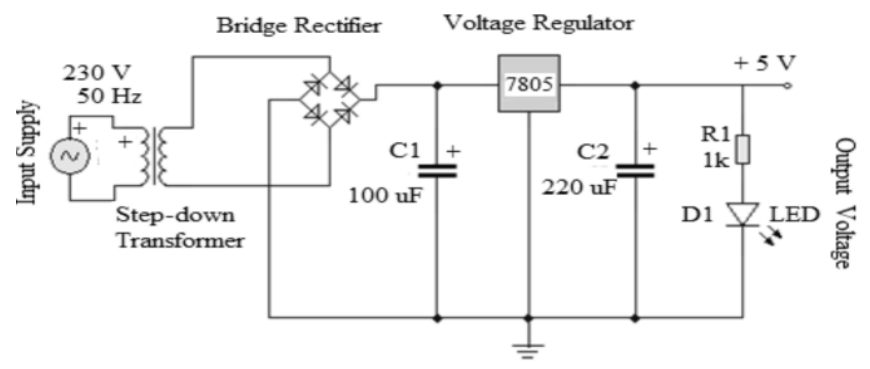

Figure 2. Power supply schematic

APTIKOM J. CSIT Vol. 2, No. 2, $2017: 77-85$ 


\subsection{LM35 and PIC interfacing}

Many of the commonly used sensors available these days include remote sensing, infrared, accelerometer, humidity sensors, temperature sensors and many others (motion sensors, alcohol sensors, gas sensors and touch screens). Most of these sensors are analogue in their natural work. This means that it gives direct and linear changes in the output voltage proportional to amount of sensor and according to there environment working conditions. In case of LM35 temperature sensor the output voltage varies according to the temperature change so that if the output voltage is $10 \mathrm{mv}$ per one degree centigrade, that means if output is $100 \mathrm{mv}$ then the temperature is 10 degrees. Therefore it is very important to know how to interface LM35 sensor with PIC16F887 MCU in order to exit with a right decision. The interfacing is needed because most of MCUs are digital device. This means if the input level greater than $2.5 \mathrm{v}$ therefore the device work as the input with high state logic one and if it is below this level (2.5v) the device read as logic low (zero volt). Based on the clarifications above it is impossible to measure voltage directly from MCUs. Therefore, to find solutions to this problem, the manufacturers and designers of MCUs put the mechanism of conversion analog to digital (ADC) within most currently MCUs available in the markets. In this case the analog voltage is converted to a corresponding number so that it can be handled and processed in MCUs without any problem. These facilitate easy interaction approximately to all types of analog devices with MCUs. The resolution represent a very another important element for ADCs. Because it determines the accuracy of the "ADC" measurement of input analog signals. Commonly ADCs used are eight bit, ten bit and twelve bit. If the reference voltage of ADC is logic zero (0 volt) to logic high ( 5 volt) then a 10 bit ADC will stop it in 1024 division so the accurately that can measure up to $5 / 1024=4.8 \mathrm{mv}$ approx. Another important factor for working with ADC is the reference voltage (ADCRV). Determining the minimum and maximum limits for voltages of analog inputs has specified by ADCRV. The PIC16F887 contains two reference voltage, the first called the positive reference voltage (+Vref), which represents the upper or maximum limit of the incoming analog input signal voltage and the second represents the negative reference voltage (-Vref), which represents the minimum input analog signal voltages. Therefore, in most simple applications, this -Vref is linked to the GND and the + Vref connected to VCC. To activate PIC16F887 to work as 10 bit ADC, the ADC unit must gives us the value between ( 0 to 1023 ) for input voltage range of zero to five volt. So if the reading is zero then the input is zero volt, if the reading is 1023 then the input is 5 volt.

\subsection{Suggested flow chart}

The logical representation of the proposed system software code has been presented in the flowchart as illustrated in Figure 3.

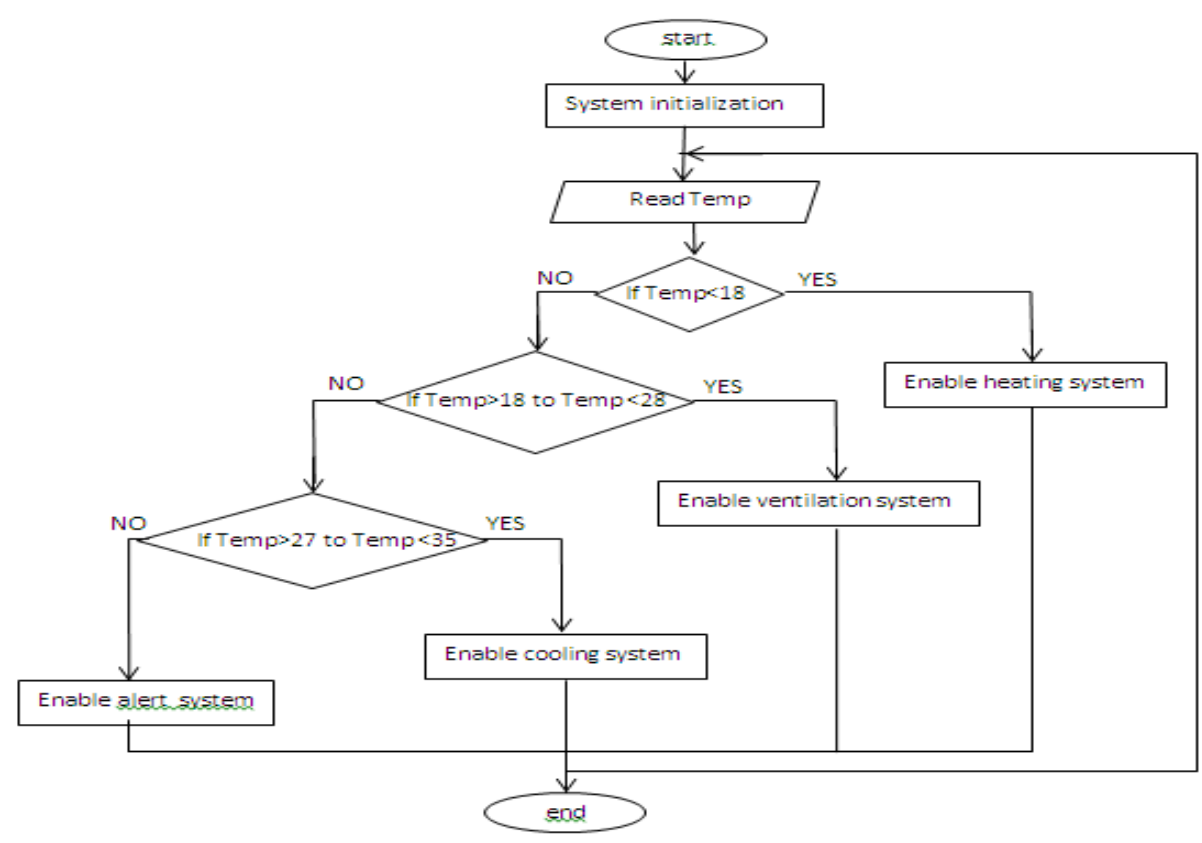

Figure 3. Flowchart of the system 
In the suggested flowchart clearly shows how the temperature control system working for control of three appliance (heating, ventilation and cooling) and one alert system depend on the temperature input value. The work of those functions can be illustrated as follows:

1. IF the temperature degree less than 18 centigrade, the case one will work that enable the heating system.

2. IF the temperature degree range between 18 and 28 centigrade the system in second case will work that enable the ventilation system.

3. IF the temperature degree between the range 28 and 35 centigrade the there'd system will work that enable cooling system.

An addition to three cases above a security factor will added to generate signal to enable alert device this is done when the temperature increase to grater than 35 centigrade.

\section{System Implementation}

The suggested system is implemented using PIC16F887 the hardware proposed design requirements as shows in Figure 4.

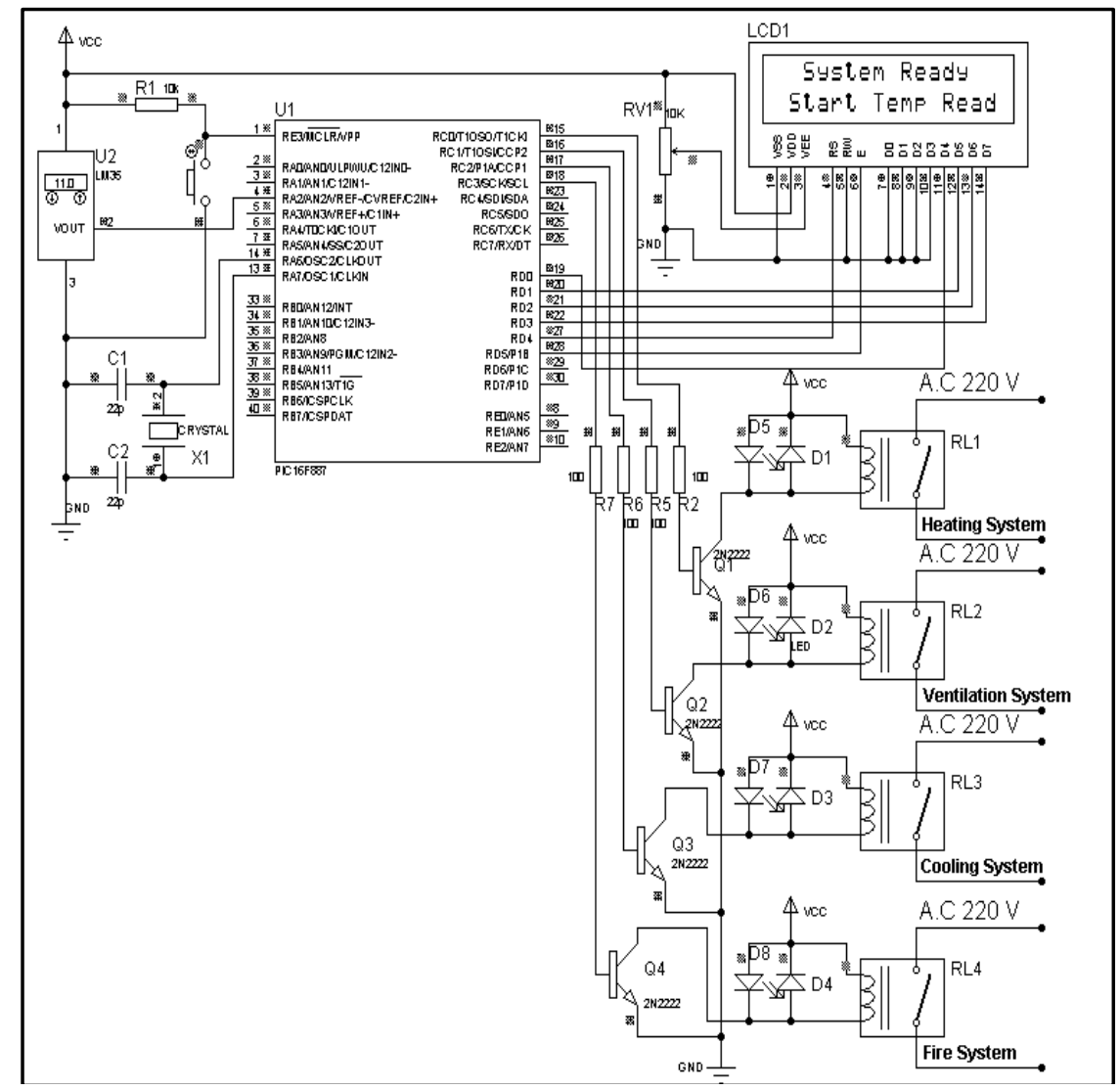

Figure 4. Hardware circuit diagram

\section{Circuit Implementation Simulation, Testing and Results}

The suggested system has been implemented and simulation by using proteus professional software v8.0 and mikroC PRO FOR PIC program. 16X2 LCD display which is used to display the system working status. The conditions that are checked and then for the purpose of choosing the type of work mode are done by relying on the temperature values that are read from the temperature sensor. The result will output and clear notes by LCD reading and corresponding LED light. This is will carefully explain in the following working modes of the system:

APTIKOM J. CSIT Vol. 2, No. 2, $2017: 77$ - 85 


\subsection{Start Mode}

The circuit diagram in the Figure 4. Above shows the initialize state. This is represent the start system work that must first initialize all the system cases before the working cases take please, this done by the initial setting of the program code. At this mode all the relays must be inactivated, all LEDs turn off and all control signal from PORTC must be at logic zero (disable) and addition of all the above, the LCD will display the message (System Ready and Start Temp Read ).

\subsection{Case 1}

The process of this mode are start when the temperature less than 18 centigrade (heating case has activate) then the heating system will enable. This is clear by the Figure 5 below with enable RCO pin of PORTC (indicated by a red color) and lighting the LED to indicate the operation of relay to allow working of heating system and LCD to display the case status that display the word (Case 1 heat and Temp LT (less than) 18).

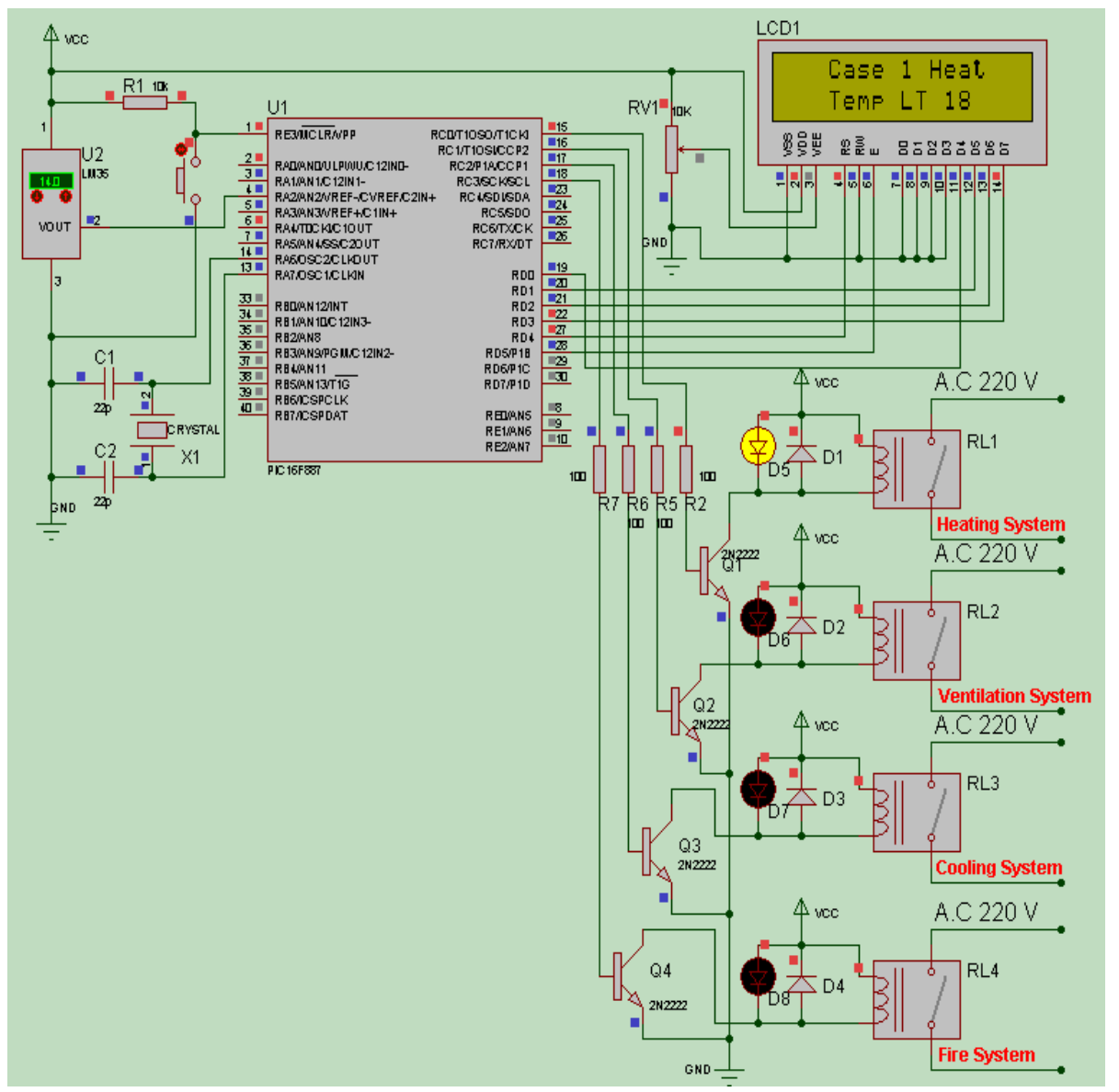

Figure 5. Heating System Circuit Diagram

\subsection{Case 2}

This working mode of the system start when the temperature equal to 18 centigrade and less than 28 centigrade (case 2 will activated i.e. ventilation system will work).

This is clear shown by the Figure 6 below with enable RC1 pin of PORTC (indicated by a red color) and lighting the LED to indicate the operation of relay to working ventilation system and LCD to display the case status that display the word (Case 2 Vent and Temp 18 TO 28). 


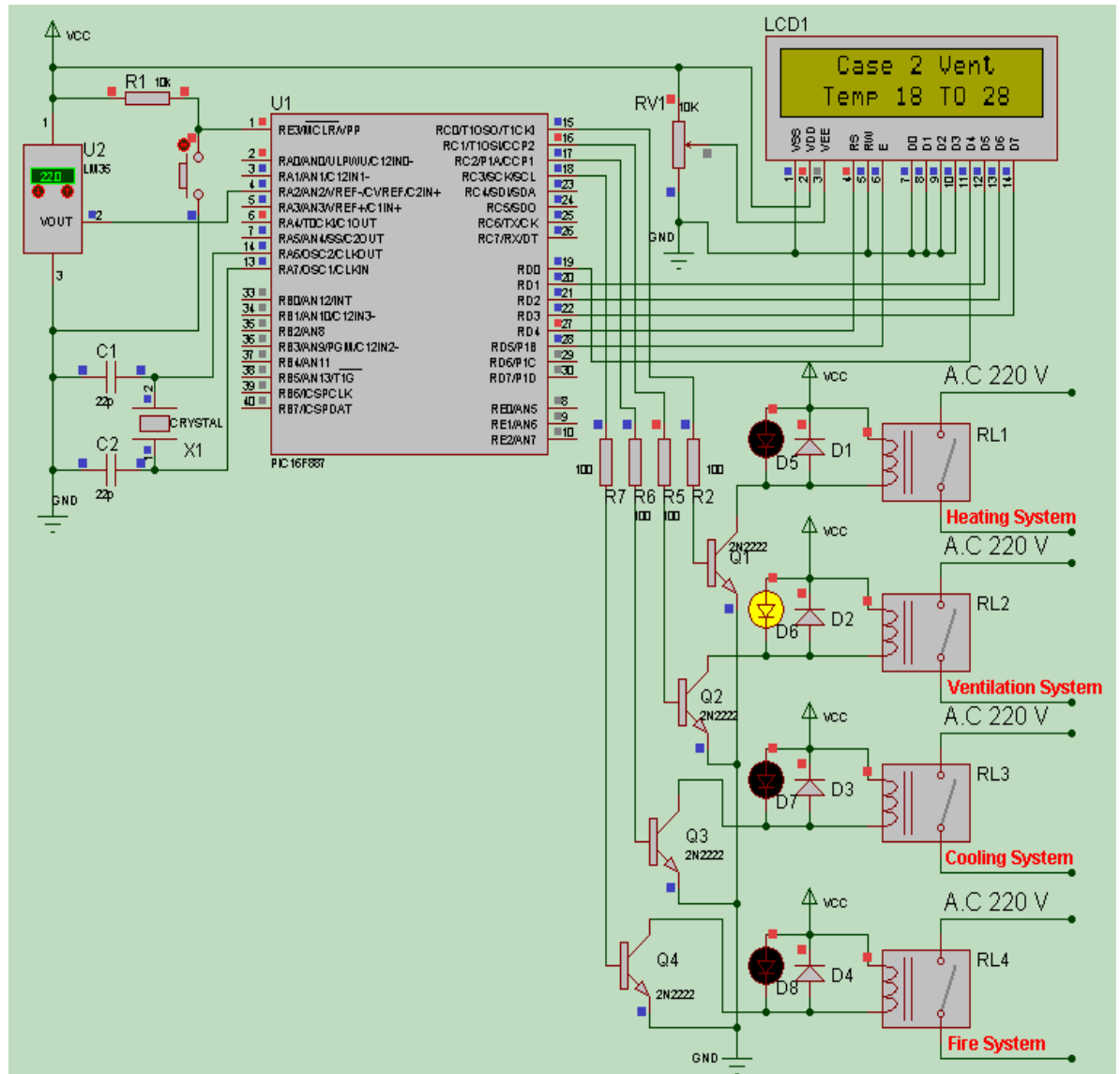

Figure 6. Ventilation System Circuit Diagram.

\subsection{Case 3}

When the temperature range from 28 to 35 centigrade (case 3 will activated i.e. cooling system will work). This is clear shown by the Figure 7 below with enable RC2 pin of PORTC (indicated by a red color) and lighting the LED to indicate the operation of relay to working heating system and LCD to display the case status that display the word (Case $3 \mathrm{Cool}$ and Temp 28 TO 35). 


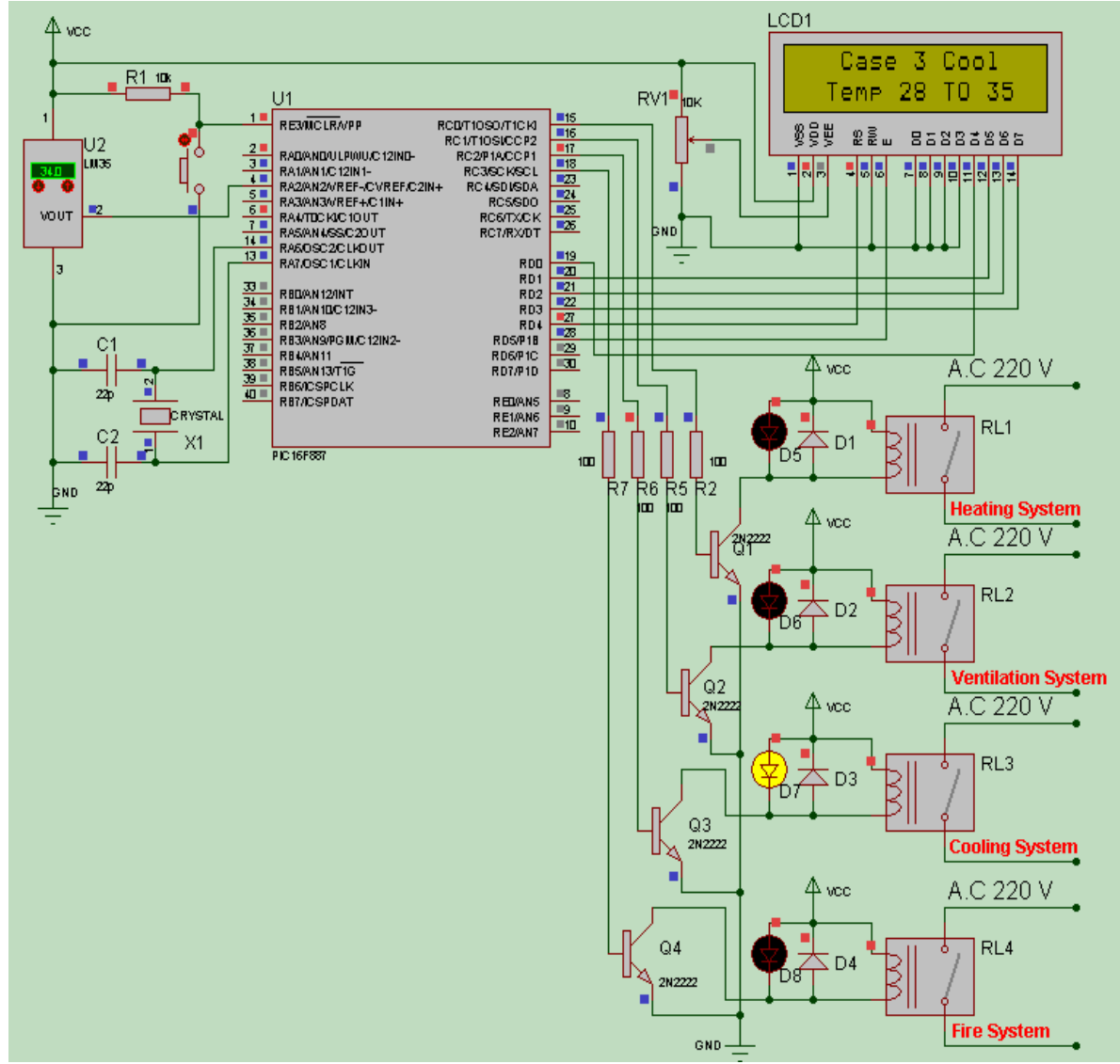

Figure 7. Cooling System Circuit Diagram.

\subsection{Alert System}

This is another working mode represent a safety feature of the system. It is accomplished when the temperature will increase to reach the value grater than 35 centigrade, alert signal will generated at the pin RC3 from PORTC of the MCU to enable the relay driver and lighting attendant LED and so by using a buzzer to produce the alert tools to work fire system, also display the word (Alert and Fire Fire) will write at the LCD display. All process of this mode are shown in the Figure 8 below. 


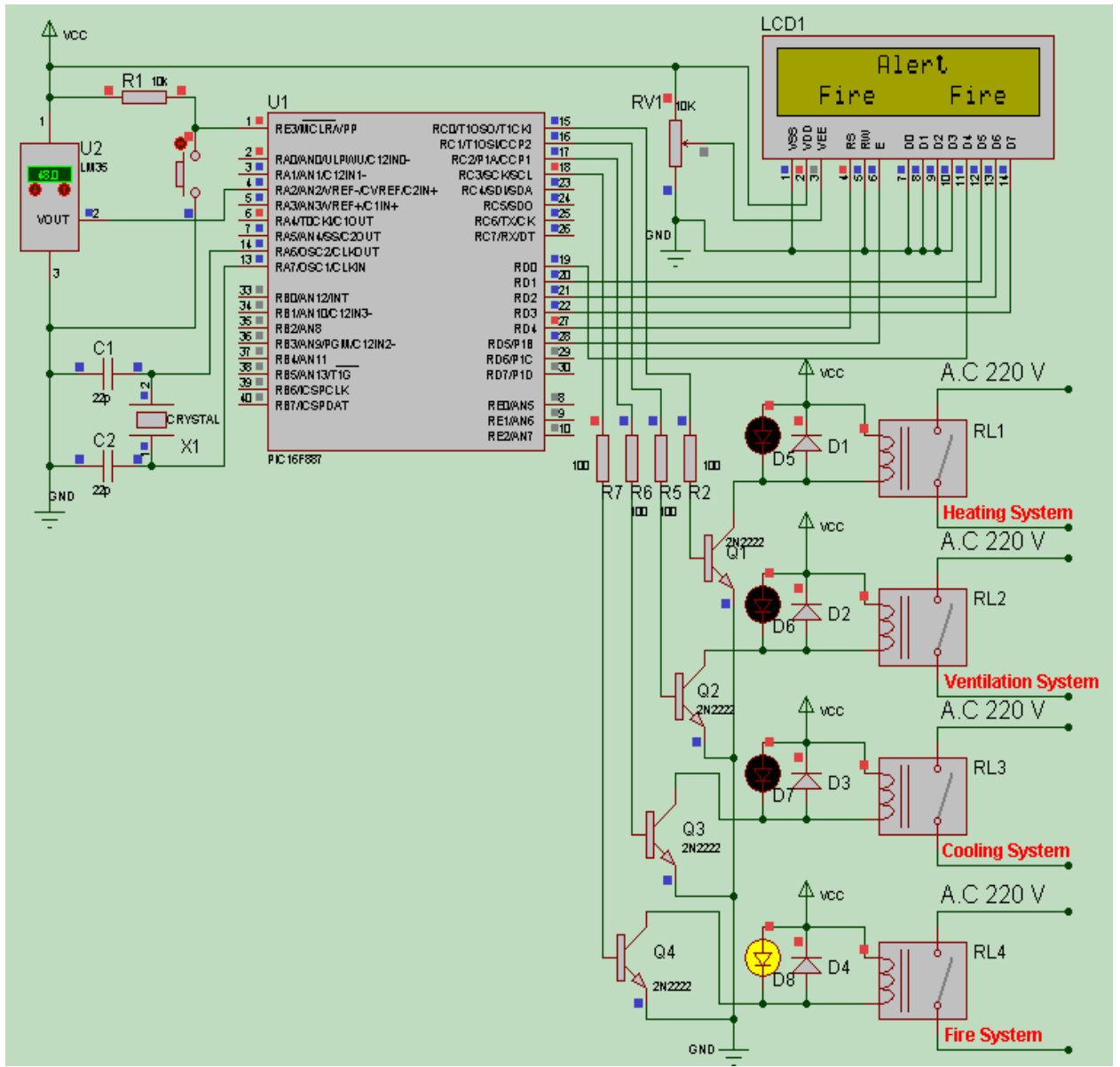

Figure 8. Fire system circuit

All system working cases resulting may be summarized at Table 1 below:

Table 1. System working cases

\begin{tabular}{|c|c|c|c|c|}
\hline $\begin{array}{c}\text { Temp. sensor } \\
\text { LM35 output }\end{array}$ & $\begin{array}{c}\text { Case 1 } \\
\text { Heat, ON }\end{array}$ & $\begin{array}{l}\text { Case 2 } \\
\text { Vant, ON }\end{array}$ & $\begin{array}{l}\text { Case 3 } \\
\text { Cool. ON }\end{array}$ & $\begin{array}{l}\text { Alert } \\
\text { Fire ON }\end{array}$ \\
\hline 0 & ON & OFF & OFF & OFF \\
10 & ON & OFF & OFF & OFF \\
15 & ON & OFF & OFF & OFF \\
17 & ON & OFF & OFF & OFF \\
18 & OFF & ON & OFF & OFF \\
19 & OFF & ON & OFF & OFF \\
20 & OFF & ON & OFF & OFF \\
21 & OFF & ON & OFF & OFF \\
22 & OFF & ON & OFF & OFF \\
23 & OFF & ON & OFF & OFF \\
24 & OFF & ON & OFF & OFF \\
25 & OFF & ON & OFF & OFF \\
26 & OFF & ON & OFF & OFF \\
27 & OFF & ON & OFF & OFF \\
28 & OFF & OFF & ON & OFF \\
29 & OFF & OFF & ON & OFF \\
30 & OFF & OFF & ON & OFF \\
31 & OFF & OFF & ON & OFF \\
32 & OFF & OFF & ON & OFF \\
33 & OFF & OFF & ON & OFF \\
34 & OFF & OFF & ON & OFF \\
35 & OFF & OFF & ON & OFF \\
36 & OFF & OFF & OFF & ON \\
37 & OFF & OFF & OFF & ON \\
38 & OFF & OFF & OFF & ON \\
\hline
\end{tabular}




\section{Conclusion and Idea for Future}

In this paper a proposed ATC simple and low cost for general applications temperature control system using PIC16F887 was design and simulation. The use of this system helps to maintain the temperature within certain limits, depending on the automatic control of the operation of the appropriate system with each temperature change and thus possible to invest in important places such as food warehouses, medical materials, laboratories, central switches, electronic servers and others that require maintaining a certain temperature limit without interference or presence of the human factor as well as guidance and send an alarm when the temperature rise and reach the dangerous stages. Think this system is very appropriate because of its simplicity and reliability in addition to small size, low cost, low power consumption in addition to all above facilities can be used for different places. In the future, there are several possible improvements can be made in order to upgrade the features such as using a GSM I/O devices to send the alert message for wide word instead of using local alert devices and may be using a wireless technologies to interface sensor, monitor relays and microcontroller.

\section{References}

[1] A. Goswami, T. Bezboruah,T. and K.C.Sarma, "Design of an embedded and implementation of an Embedded system for monitoring and controlling the intensity of light", proceeding of the 2008 international conference on embedded systems and application during july 14-17,2008 at Las Vegas Nevada, USA, Vol.-ESA 2008, pp.117-123.

[2] A.Goswami, T. Bezboruah, K.C. Sarma., "An Embedded Design for Automatic Temperature Controller", International Journal of advanced engineering and application, Jan 2011.

[3] June Tharaphe Lwin1, Aung Ze Ya " Development of Microcontroller Based Temperature and Lighting Control System in Smart Home" International Journal of scientific engineering and technology research July2014 pages: $3322-3327$.

[4] N. A. A. Hadi, M. H. C. Hasan, N. M. Z. Hashim, A. Salleh, A. A. Salam, Z. Hasan " Automatic Smart Kitchen System Using Microcontroller" International Journal for Advance Research In Engineering And Technology Volume 3, Issue VI, June 2015 ISSN 2320-6802

[5] S.R.Sharma1, P.B.Dahikar "embedded design of temperature controller using PIC 16F876A for industries and laboratories" International Journal of Innovative Research in Computer and Communication Engineering Vol. 1, Issue 10, December 2013.

[6] Bogdan Levărdă and Cristina Budaciu, "The Design Of Temperature Control Systemusing Pic18f4620" Buletinul Institutului Politehnic Din Iasi Publicat de Universitatea Tehnică „Gheorghe Asachi” din Iasi Tomul LVI (LX), Fasc. 4, 2010 SecŃia Automatică si Calculatoare.

[7] Mustafa Saad, Hossam Abdoalgader, and Muammer Mohamed "Automatic Fan Speed Control System Using Microcontroller" 6th Int'l Conference on Electrical, Electronics \& Civil Engineering (ICEECE'2014) Nov. 27-28, 2014 Cape Town (South Africa).

[8] Theophilus Wellem and Bhudi Setiawan " A Microcontroller- based Room Temperature Monitoring System" International Journal of Computer Applications (0975 - 8887) Volume 53- No.1, September 2012.

[9] Vaibhav Bhatia and Gavish Bhatia "Room Temperature based Fan Speed Control System using Pulse Width Modulation Technique" International Journal of Computer Applications (0975 - 8887) Volume 81 - No5, November 2013. 